Foro presenta opiniones disidentes dentro del campo de la biología y considera para publicación respuestas de nuestros(as) lectores (as).

Forum presents dissident opinions in the field of biology and considers for publication formal replies from our readers.

\title{
Del mecanicismo a la complejidad en la biología
}

\author{
Libia Herrero Uribe \\ Centro de Investigación en Enfermedades Tropicales, Facultad de Microbiología, Universidad de Costa Rica. San \\ José, Costa Rica. lherrero@cariari.ucr.ac.cr
}

Recibido 30-VIII-2006. Corregido 21-V-2007. Aceptado 27-VII-2007.

\begin{abstract}
From the mechanical complexity in biology. Through history, each century has brought new discoveries and beliefs that have resulted in different perspectives to study life organisms. In this essay, I define three periods: in the first, organisms were studied in the context of their environment, in the second, on the basis of physical and chemical laws, and on the third, systemically. My analysis starts with primitive humans, continues to Aristoteles and Newton, Lamarck and Darwin, the DNA doble helix discovery, and the beginnings of reduccionism in science. I propose that life is paradigmatical, that it obeys physical and chemical laws but cannot be explained by them I review the systemic theory, autopoiesis, discipative structures and non- linear dynamics. I propose that the deterministic, lineal and quantitative paradigm of nature are not the only way to study nature and invite the reader to explore the complexity paradigm. Rev. Biol. Trop. 56 (1): 399-407. Epub 2008 March 31.
\end{abstract}

Key words: organisms, history, perspectives, mecanicism, complexity.

A través de la historia, los organismos vivos han sido estudiados bajo muy diferentes puntos de vista en relación con el ambiente. Cada época ha introducido nuevas experiencias y conocimientos que han desarrollado nuevas perspectivas para estudiar y definir los organismos vivos. Me he permitido dividir el análisis en tres etapas que pueden distinguirse en la historia, la primera ligada al ambiente que rodea al ser humano, la segunda basada en las leyes de la química y la física y la tercera, integral o sistémica. En la figura 1, se muestran las tres etapas y se posicionan los acontecimientos más preponderantes según mi criterio para mostrar la evolución de los descubrimientos y pensamientos que han influido en las diferentes perspectivas que se han utilizado para analizar la vida. Esta figura sirve de guía para el análisis que se presenta en este trabajo. El cono de la parte superior se encuentra cerrado, ya que al principio, la tierra era el centro del Universo. El $\mathrm{ADN}$ se posiciona en la parte central de la figura por el impacto que tuvo el descubrimiento de la doble hélice en la investigación en biología. El final del cono inferior, muestra las nuevas teorías de la ciencia de la complejidad, los multiuniversos, los mundos paralelos y sus implicaciones para los seres humanos. En los cuerpos de los conos, se posicionan las nuevas teorías y conocimientos que llevan de arriba para abajo al reduccionismo y del centro hacia abajo a lo sistémico.

Los primitivos Homo sapiens podrían haber clasificado los seres vivos de acuerdo con sus necesidades: aquello que se dejaba recolectar o lo que se debía cazar, lo dulce de lo amargo y lo venenoso o beneficioso para su supervivencia. En esta etapa es clara la relación que existía con el ambiente, la cual permanece hasta el tiempo de Aristóteles quien introduce la formulación del orden cósmico al exponer sus nociones holísticas y teleológicas con su famosa frase "El todo es más que la suma de sus partes". Desde el tiempo de Aristóteles, los organismos vivos se dividieron en dos grandes grupos: Animales y Plantas. En 1735, Carl 


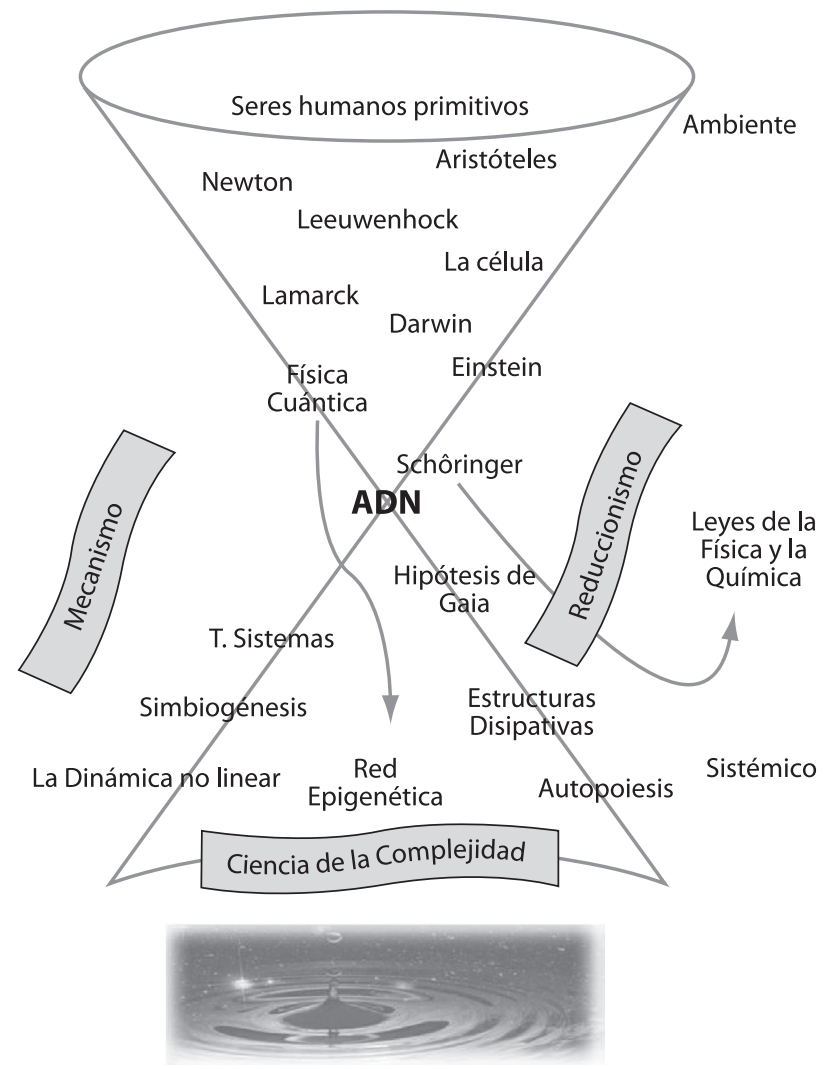

Fig. 1. Algunas teorías y descubrimientos que influyeron en el estudio de los organismos vivos a través de la historia.

von Linnaeus (Smith 1976) publicó Sistema Naturae donde presenta la primera clasificación de todos los organismos vivos y los agrupa básicamente de acuerdo a similitudes, según la observación de su entorno. Isaac Newton, considerado el científico de todos los tiempos por el descubrimiento de la ley de la gravedad, de las leyes de la mecánica y del movimiento revoluciona el mundo hasta ese entonces conocido, pero a mi criterio, en la biología, el impacto de ver el universo como una máquina no inicia hasta el descubrimiento de la célula, ya que a partir de este hecho es que se comprende que los organismos vivos están hechos de unidades estructurales básicas.

A partir del descubrimiento del mundo microscópico, a finales del siglo XVII, por Anton van Leeuwenhoek (1677) se da el inicio al estudio de un mundo de gran abundancia y diversidad que lleva al descubrimiento de la célula, y permite a Matías Schleiden y Theodor Schwann (Smith 1976) presentar, en forma independiente, "la doctrina de la célula: las plantas y los animales no son un todo indivisible, sino que son compuestos, hechos de innumerables células, y cada célula en sí misma es un organismo, con los atributos esenciales de la vida. Cada célula vive una doble vida: una independiente, ocupándose por su propio desarrollo; y otro incidental, ya que se ha convertido en parte integral de la planta".

Años después, Rudolf Virchow (Smith 1976) publica su frase categórica, que sigue siendo una verdad esencial en biología, "Omnis cellula e cellula" donde afirma que cada célula viene de una célula, es decir que las células no se originan de forma espontánea.

Los primeros evolucionistas como Jean Baptiste Lamarck (1984) y Charles Darwin (1859) basan sus teorías en la observación 
y el estudio de los organismos y explican su evolución según la necesidad de adaptación a su ambiente. Ambos insisten que todos los organismos aparecen por evolución y son un continuum filogenético. Entre más semejantes los organismos, más relacionados están y tienen un ancestro común. La diferencia fundamental entre los dos fue que Lamarck creía que las características obtenidas por los organismos para adaptarse al ambiente eran heredadas a la siguiente generación, en cambio Darwin basó su teoría en dos ideas fundamentales: la variación al azar (denominada más tarde mutación aleatoria) y la selección natural.

Hasta los años cuarenta del siglo XX, la biología se estudió enfocada en los organismos vivos, es decir en las células, ya que éstas se consideraban los componentes estructurales básicos. Después de la segunda guerra mundial, el estudio de los organismos vivos empieza a explicarse desde la física y la química a raíz del libro ¿Qué es la Vida? del famoso físico Erwin Schrödinger (1944). Aunque él mismo aceptaba que el estudio de los seres vivos no puede basarse solamente en el conocimiento existente en ese momento, estaba seguro que el problema se resolvería cuando se descubrieran otras leyes de la física hasta el momento desconocidas. Esta nueva visión se intensificó con el descubrimiento de la estructura de la molécula del ADN por Watson y Crick en 1953. Este hecho cambió la perspectiva del estudio de la vida, dándole un lugar especial a la genética y direccionando completamente la investigación biológica. Mientras que las células se veían como los componentes básicos de los organismos vivos durante el siglo XIX, la atención cambió de las células a las moléculas. Aquí se inicia el período más duro de la visión reduccionista de la biología.

A principios del siglo XX, la teoría de relatividad de Einstein, y las diferentes interpretaciones de la física cuántica, traen un cambio de paradigma del mundo mecanicista de Descartes y Newton hacia la visión sistémica. Es decir, que el Universo deja de ser visto como una máquina compuesta de partes, y se introduce una visión de integración, de interdependencia.
Aunque la física cuántica se desarrolla durante los primeros 30 años del siglo XX, sus implicaciones filosóficas han sido muy difíciles de aceptar ya que integrarla llevaría al ser humano a relacionarse con el Universo de una forma totalmente diferente (Bohm 1951, 1980).

Heisenberg (1971) por otro lado, discute que lo que observamos, no es la naturaleza en sí misma, sino la naturaleza expuesta a nuestro método de observación, de manera que el método de cuestionar se convierte en parte integrante de las teorías científicas. De esta manera, el pensamiento sistémico comporta un cambio de ciencia objetiva a ciencia "epistémica", a un marco en que la epistemología - el modo de cuestionar - se convierte en parte integrante de las teorías científicas. Esta forma de pensamiento y análisis todavía no es aceptada por muchas de las ciencias llamadas duras.

En los años 50s, von Bertalanfyy (1950) describe la teoría de los sistemas que retoma el concepto aristotélico "el todo es más que la suma de sus partes". Comprender las cosas sistémicamente significa literalmente colocarlas en un contexto, establecer la naturaleza de sus relaciones. En la visión sistémica, los objetos en sí mismos son redes de relaciones inmersas en redes mayores. Para el pensador sistémico las relaciones son prioritarias. Durante los años cincuenta y sesenta, el pensamiento sistémico tuvo gran influencia en la ingeniería y la gestión de empresas, pero su incidencia en el campo de la biología fue paradójicamente casi inexistente (Figura 1). De manera que, el estudio de la biología se mantuvo desde el mecanicismo, que explica la vida desde las leyes de la física y la química.

Grunther Stent (1978) discute sobre la calidad paradójica de los organismos vivos, que obedecen a las leyes de la física y la química, pero que sin embargo no pueden ser explicados en término de esas ciencias. En este nuevo contexto, en los años setenta el filósofo Arne Naes (Devall y Sessions 1998) desarrolla un movimiento filosófico conocido como la ecología profunda, la cual reconoce el valor intrínseco de todos los seres vivos y ve a los humanos como una mera hebra de la trama de la vida. 
A finales del siglo $\mathrm{XX}$, debido a una serie de problemas globales que dañan la biosfera, la extinción en gran escala de especies de animales y plantas, la reemergencia y emergencia de agentes infecciosos y la desigualdad alarmante entre los seres humanos, los temas del ambiente adquirieron una importancia primordial. Cuanto más se estudian los problemas de nuestro mundo, más se evidencia que no pueden ser entendidos aisladamente. Se trata de problemas sistémicos, lo que significa que están interconectados y son interdependientes.

Dentro de esta nueva perspectiva, aparece la hipótesis de Gaia (Gaia viene de la Diosa griega Madre Tierra) en que James E. Lovelock (2000) postula que el planeta Tierra se comporta como un superorganismo que tiende a la autorregulación. Con la colaboración de Lynn Margulis (Margullis y Lovelock 1974), quien en ese momento estaba estudiando los procesos por los cuales los microorganismos producen y remueven gases de la atmósfera, logran describir un número de anillos de retroalimentación que podrían actuar como influencias regulatorias. La base fundamental de esta hipótesis es el desequilibrio existente en los gases de la bioesfera y que son los organismos vivos los que tienen la potestad de llevar a cabo esta regulación. Como lo describe Lynn Margulis (1998) en su libro Symbiotic Planet "Gaia es simbiosis vista desde el espacio: todos los organismos se están tocando por que todos están bañados en el mismo aire y la misma agua que fluye". Esta hipótesis cada día es más aceptada por el mundo científico, pero se prefiere describirla como el Sistema Científico de la Tierra o de Geofisiología (Lovelock 2000).

En los últimos años, los matemáticos se unen al estudio de los organismos vivos por medio de la formulación de una teoría de los sistemas vivientes al desarrollar un conjunto de conceptos matemáticos y técnicas que describen y analizan la complejidad de los sistemas vivientes. Esta nueva metodología se ha llamado "la teoría de la complejidad" o "la ciencia de la complejidad" o como les gusta llamarla a los matemáticos "la dinámica nolinear" (Capra 1996).
La no-linealidad es una consecuencia frecuente en las interacciones de retro-alimentación que es común en los procesos de regulación en los organismos vivos. Esta nueva matemática de la complejidad explica cómo las formas biológicas y las funciones de un organismo no están determinadas solo por las características genéticas del organismo sino que son propiedades emergentes de toda la red epigenética (interrelación entre el núcleo y el citoplasma de la célula). Para entender la emergencia de formas nuevas, se necesita entender no solo la estructura genética y la bioquímica celular sino también su relación con el ambiente. Este encuentro entre la célula y el ambiente da como resultado un número ilimitado de posibles funciones y formas. Esto es demostrado por medio de ecuaciones complejas y patrones geométricos que representan las propiedades dinámicas de los sistemas (Capra 1996, Keller 2000).

Una de las teorías más aceptadas en la actualidad para definir los organismos vivos es la formulada en 1980 por los científicos chilenos Humberto Maturana y Francisco Varela (Maturama y Varela 1980). Ellos proponen su teoría de la autopoiesis, Auto, significa "sí mismo" y se refiere a la autonomía de los sistemas autoorganizados. Poiesis significa "poesía=creación", por lo tanto significa "hacerse a sí mismo". La organización de los sistemas vivos se trata de una red de procesos de producción, en la que la función de cada componente es participar en la producción o transformación de otros componentes de la red. De esta forma, toda la red se hace a sí misma continuamente. Es producida por sus componentes y, a su vez, los produce. En un sistema vivo-dicen los autores- el producto de su operación es su propia organización. Una importante característica de los sistemas vivos es que su organización autopoiética incluye la creación de un perímetro que especifica el territorio de las operaciones de la red y define el sistema como una unidad. Como dice Pier Luigi Luisi (1993) "La vida no puede ser adscrita a ningún componente molecular por sí mismo, sino a toda la red metabólica interconectada". 
Estudios detallados sobre el flujo de la energía a través de sistemas complejos resultaron en la teoría de estructuras disipativas desarrollada por Ilya Prigogine y sus colaboradores (Prigogine y Stengers 1984). Una estructura disipativa se describe como un sistema abierto que se mantiene a sí mismo en un estado lejos del equilibrio, pero es estable: su estructura se mantiene aunque esté ocurriendo un constante flujo y cambio de componentes. Prigogine, escogió el término estructuras disipativas para enfatizar este intercambio cerrado entre estructura por un lado y flujo y cambio (disipación) por el otro. La dinámica de estas estructuras disipativas incluye la emergencia espontánea de nuevas formas del orden en puntos críticos de inestabilidad o puntos de bifurcación. Prigogine enfatiza que las características de una estructura disipativa no pueden deducirse de las propiedades de sus partes, sino que son consecuencia de su "organización supramolecular". Aparecen correlaciones de largo alcance en el mismo punto de transición de equilibrio a no-equilibrio, y a partir de este punto, el sistema se comporta como un todo. Lejos de equilibrio, los procesos fluyentes del sistema están vinculados a través de múltiples bucles de retroalimentación y las ecuaciones matemáticas correspondientes son no-lineares. Cuanto más alejado del equilibrio está un sistema, mayor es su complejidad y más alto el grado de no-linealidad (Capra 1996). Es técnicamente reconocido como auto-organización o "emergencia", en otras palabras, creatividades una propiedad fundamental de los sistemas vivos. La teoría de las estructuras disipativas, formulada en términos de la dinámica nolinear, no solo explica la emergencia del orden sino que también ayuda a definir la complejidad y la asombrosa creatividad de la vida.

A pesar de todas las nuevas teorías y perspectivas para el estudio de los organismos vivos, algunos científicos mantienen el criterio que cada fenómeno biológico, por complejo que sea, está basado en interacciones químicas y físicas entre las moléculas. Pero la complejidad que caracteriza a los seres vivos, sus estructuras y función, metabolismo, reproducción, adaptación y su comportamiento hacia la búsqueda de una meta llevan a la pregunta si el estudio de la biología puede realmente reducirse a la química y a la física o si debe ser una ciencia autónoma con principios propios (Capra 2002).

Aunque el darwinismo y el neodarwinismo han sido la base para explicar el origen de las especies, la diversidad de los organismos, la evolución y el orden biológico, no explica los grandes cambios evolutivos que se observan en los fósiles, ya que éstos demuestran que la transformación de las poblaciones no es ni lenta ni mantenida, como lo sugieren Darwin y Wallace. Stephen Jay Gould, en 1982, argumenta que el darwinismo no es que sea incorrecto para explicar la evolución, sino que necesita expandirse sobre todo en su aplicación al origen de nuevas especies y categorías superiores. Es así como propone en conjunto con Eldredge (Eldredge y Gould 1973) un nuevo modelo de patrón de evolución, el "equilibrio interrumpido" en donde explican que durante largos períodos de constancia relativa en las especies, existen cambios rápidos y abruptos por episodios puntuales, los cuales generan nuevas especies. Gould y Eldregde (1993), creen que la evolución es más rica y más innovadora de lo que la ortodoxia permite, gracias a la infusión de novedades no adaptativas, brincos episódicos y una buena dosis de eventualidad.

Por otro lado, el anatomista Ivan E. Wallin (1927) argumenta en su libro Symbioticism and the Origin of Species que nuevas especies se originan por medio de la simbiosis. Años después, Lynn Margulis (1998) establece el término evolucionista "simbiogénesis", que se refiere al origen de nuevos tejidos, órganos, organismos y hasta nuevas especies por medio del establecimiento de simbiosis permanentes o por largos períodos entre organismos. Es un cambio evolutivo por la herencia del conjunto de genes adquiridos por los padres. La simbiosis para Margulis es crucial para entender novedades evolutivas y el origen de nuevas especies y no es un evento marginal o raro, al contrario es un evento común en la naturaleza. En sus propias palabras: "la simbiosis es como un resplandor de un rayo en la evolución". 
Jean Baptiste Lamarck decía que los organismos heredan las características de sus padres que fueron inducidas por el ambiente; de esta forma Lynn Margulis (1998) dice que la simbiogénesis es un tipo de neo-lamarckismo ya que los organismos adquieren no las características inducidas por el ambiente, sino organismos enteros con su conjunto de genes. El origen de células de plantas y animales por medio de la simbiosis ya no es controversial, ya que la biología molecular lo ha demostrado utilizando métodos de secuenciación de ácidos nucleicos.

Cada día aparecen más informes en la literatura científica sobre la transferencia horizontal de genes, la cual ocurre entre organismos de la misma especie y hasta entre un Filo y un Reino. Esta promiscuidad genética entre los organismos vivos lleva a la duda en el momento de definir el linaje de una especie a través de la transmisión vertical (sus propios genes?) de padres a hijos (Margulis 1998, Keller 2002).

Los virus son muy importantes en la transferencia de genes, lo hacen entre bacterias, entre humanos y otras células, haciéndolos también parte de cambios evolutivos. Las poblaciones de organismos infectados por virus son asideros de selección natural, y como dice Lynn Margulis (1998) "nosotros somos nuestros virus".

En los años 70, los problemas con el Dogma Central se volvieron más evidentes cuando los investigadores extendieron sus trabajos más allá de las bacterias. Se encontró que la correspondencia entre las secuencias de ADN y las secuencias de aminoácidos en las proteínas no existe en los organismos más complejos. Por lo tanto, el principio de un gen- una proteína tuvo que ser abandonado. En organismos superiores, los genes que codifican las proteínas tienden a estar fragmentados más que ser una secuencia continua. De manera que muchas proteínas pueden ser producidas de la misma secuencia genética primaria; a veces hasta varios cientos de ellas de acuerdo con los últimos estimados (Ast 2005). Según este mismo autor, "la señal o señales que determinan el patrón específico en que el transcripto final es formado viene de la regulación dinámica compleja de la célula como un todo. Descifrar la estructura de las vías de dicho señalamiento se ha convertido en el foco principal de la biología molecular contemporánea". Hoy en día se ha demostrado que un organismo entre más complejo sea, extrae múltiples proteínas de un solo gen. Esto se comprueba cuando se realiza la secuenciación del genoma humano donde se han identificado 25.000 genes y se conoce que el ser humano sintetiza alrededor de 100.000 proteínas. El mecanismo que se utiliza es el de "edición alternativa" (Ast 2005), lo que significa que el código genético que presenta cada gen es leído utilizando diferentes sitios de iniciación, lo que se traduce en proteínas de diferentes secuencias de aminoácidos y por lo tanto de conformación y función diferente.

Las investigaciones, por lo tanto, han demostrado que el programa de activar los genes no reside en el genoma, sino en la red epigenética de la célula. Una serie de estructuras celulares se han identificado en la regulación de la expresión de un gen. Estas incluyen proteínas estructurales, hormonas, redes de enzimas y muchos otros compuestos moleculares. En particular, la cromatina parece jugar un rol crítico, ya que constituye el ambiente más cercano al genoma (Mattick 2004).

La herencia epigenética es la transmisión de información de una célula o un organismo multicelular a sus descendientes sin que esa información esté codificada en la secuencia de nucleótidos de su ADN. El sistema de herencia epigenética le permite a las células de fenotipos diferentes e iguales genotipos transmitir su fenotipo a los descendientes, aunque el estímulo responsable de inducir esa característica esté ausente. Un gen puede ser estimulado directa $\mathrm{o}$ indirectamente para transcribir un producto que mantiene la actividad de ese gen. Los descendientes de esa célula pueden heredar esa actividad aunque el estímulo que activó el gen ya no esté. La difusión del producto de ese gen puede pasarle esa característica a las células vecinas (Keller 2002).

Los nuevos descubrimientos como la edición alternativa (Ast 2005), el origen de la complejidad del genoma (Lynch y Conery 2003) 
y la red epigenética (Mattick 2004, Schaefer et al. 2007) llevan a la sugerencia que las actividades del genoma están reguladas por las redes celulares en las cuales está embebido. Esta red es no-linear, conteniendo múltiples bucles de retroalimentación, de manera que los patrones de actividad genética continuamente están cambiando en respuesta a circunstancias cambiantes (Strohman 1997). Lo importante de hacer notar, es que el ADN es un componente más de la red epigenética, que si bien su participación es esencial, esta molécula no tiene toda la responsabilidad de los cambios que se generan (Maturama y Varela 1987) Capra (1996), basándose en la teoría de la autopoiesis y la de estructuras disipativas, define a la célula como una entidad rodeada por una membrana, que se auto genera; es una red metabólica cerrada desde el punto de vista organizacional, la cual es un sistema abierto desde el punto de vista material y energético, utilizando constantemente un flujo de materia y energía para producir, repararse y perpetuarse. Opera lejos del equilibrio, donde nuevas estructuras y nuevas formas de orden pueden emerger espontáneamente, llevándola al desarrollo y la evolución.

El planeta Tierra es el ecosistema más grande, producido por otros ecosistemas, y éstos por redes, que a su vez se forman de más redes de retroalimentación. Todo fluye, todo se intercambia, se regenera, se transforma, se constituye, se autoorganiza. Se produce el orden y a su vez, los estados de equilibrio a no-equilibrio suceden constantemente, los puntos de bifurcación aparecen y desaparecen y en toda esta actividad incesante, se produce la impetuosa creatividad de la vida.

Para muchos científicos lo ideal sería estar entre el reduccionismo y el holismo, ya que el enfoque reduccionista es una estrategia importante para hacer investigación, y cuando es exitosa ofrece explicaciones que son satisfactorias. Hunter (1996) presenta una respuesta conciliatoria; reexaminando si la pregunta de si la biología puede ser reducida a la química, él dice: "Los dos extremos son conciliatorios, no antagonistas: para aquellos que buscan entender los organismos vivos requieren ambas, la perspectiva holística desde arriba para abajo y la perspectiva reduccionista de abajo para arriba. Ninguna de ambas es suficiente por sí misma”.

En el mundo de la complejidad, cada nivel lleva al nivel de arriba: la química lleva a la bioquímica, a la biología celular, a la fisiología, a la psicología, a la sociología, a la economía y la política (Ellis 2005). La física cuántica es la materia fundamental que explica todo lo demás, por las diferentes interpretaciones que ésta posibilita, pero no explica la intencionalidad, ni la existencia de la creatividad de la vida.

Después de todo, la vida apareció hace millones de años, ahí ha estado y la hemos ido descubriendo poco a poco según se van desarrollando nuevas tecnologías. Los organismos vivos siguen evolucionando, la ciencia sigue descubriendo mecanismos e interrelaciones nuevas, pero no se atreve a revisar sus dogmas y definiciones. La mayoría de los científicos insisten en mantenerse firmes en el paradigma de la naturaleza determinista, lineal y cuantitativa y se resisten a explorar el paradigma de la complejidad.

Esta nueva visión sin duda alguna, dará a la investigación en biología una libertad diferente que logre entender la naturaleza misma y dar posibilidad a la verdadera creatividad y con ella a nuevos descubrimientos que permitan un desarrollo más acorde con el planeta en que vivimos.

\section{AGRADECIMIENTOS}

La autora agradece a Eleonora Badilla, Mauricio Frayman, Nora Garita, José María Gutiérrez, Laya Hun y Ana Sittenfeld por sus observaciones y sugerencias.

\section{RESUMEN}

A través de la historia, los organismos vivos han sido estudiados desde diferentes puntos de vista. Presento tres etapas, la primera totalmente ligada al ambiente que rodea al ser humano, la segunda que se basa en las leyes de la química y la física, y la tercera que es integral o sistémica. Tras pasar revista a los grandes descubrimientos de los humanos primitivos hasta el descubrimiento del ADN y el inicio del reduccionismo en la ciencia,propongo 
la calidad paradójica de los organismos vivos, que obedecen a las leyes de la física y la química, pero que, creo, no pueden ser explicados en términos de esas ciencias. Analizo las teorías de sistemas y autopoiesis, las estructuras disipativas y la matemática no linear, para afirmar que el paradigma de la naturaleza determinista, lineal y cuantitativa debe dejarse de lado como la única forma de estudiar los organismos vivos e invitarle a explorar el paradigma de la complejidad.

Palabras clave: organismos, historia, perspectivas, mecanicismo, complejidad.

\section{REFERENCIAS}

Ast, G. 2005. The alternative Genome. Sci. Amer. 292: 40-47.

Bohm, D. 1951. Quantum Theory. Prentice-Hall, Nueva York, EEUU.

Bohm, D. 1980. Wholeness and the Implicate Order. Routledge \& Kegan Paul, Londres, Inglaterra.

Capra, F. 1996. La trama de la vida. Una nueva perspectiva de los sistemas vivos. Anagrama, Barcelona, España.

Capra, F. 2002. The Hidden Connections: integrating the biological, cognitive, and social dimensions of life into a science of sustainability. Doubleday, Random House, Nueva York, EEUU.

Darwin, Ch. 1859. On the Origin of the Species. Murray, Londres, Inglaterra.

Devall, B. \& G. Sessions. 1998. Deep Ecology. Peregrine Smith, Salt Lake City, Utah, EEUU.

Eldregde, N. \& S.J. Gould. 1973. "Puntuacted Equilibria: An alternative to phylogenetic gradualism", p. 82-115. In T.J.M. Schopf (ed.). Models of Paleobiology. Freeman Cooper, San Francisco, California, EEUU.

Ellis, G.R. 2005. Physics, complexity and causality. Nature 435: 743.

Gould, S.J. \& N. Eldredge. 1993. Puntuacted Equilibrium comes to age. Nature 366: 223-227.

Heisenberg, W. 1971. Physics and Beyond. Harper \& Row, Nueva York, EEUU.
Hunter, G.K. 1996. Is biology reducible to chemistry? Perspect. Biol. Med. 40: 181-203.

Keller, E.F. 2000. The Century of the Gene. Harvard, Cambridge, Massachussets, EEUU.

Keller, E.F. 2002. Making Sense of Life: Explaining biological development with models, metaphors, and machines. Harvard, Cambridge, Massachusetts, EEUU.

Lamarck, J.B. 1984 (1809). Philiosophical Zoology: An Exposition with regard to the Natural History of Animals. Chicago, Chicago, EEUU.

Lynch, M. \& Conery, J.S. 2003. The Origins of Genome Complexity. Science 302: 1401-1404.Lovelock, J.E. 2000. Gaia. A new Look at Life on Earth. Oxford, Oxford, Inglaterra.

Luisi, P.L. 1993. Defining the Transition of Life: SelfReplicating Bounded Structures and Chemical Autopoiesis. In W. Stein \& F.J. Varela (eds.). Thinking about Biology. Addison-Wesley, Nueva York, EEUU.

Margulis, L. \& J.E. Lovelock. 1974. Biological Modulation of the earth's Atmosphere. Icarus 21: 471.

Margulis, L. 1998. Symbiotic Planet. A New Look at Evolution. Brockman, Massachussets, EEUU.

Maturama, H. 1980 (1970). Biology of Cognition. Reimpreso In H. Maturama \& F. Varela. Autopoiesis and cognition the realization of the living. D. Reidel, Dordrecht, Holanda.

Maturama, H. \& F. Varela. 1987. The Tree of Knowledge. Shambala, Boston, Massachussetts, EEUU.

Mattick, J.S. 2004. The Hidden Genetic Program of Complex Organisms. Sci. Am. 291: 60-67.

Prigogine, I. \& I. Stengers. 1984. Order out of Chaos: Mans new dialogue with nature. Bantam Books, Nueva York, EEUU.

Schrödinger, E. 1944. What is life? Cambridge, Cambridge, Inglaterra.

Schaefer, C.B., S.K.T. Ooi, T.H. Bestor \& D. Boure'his. 2007. Epigenetic Decisions in Mammalian Germ Cells. Science 316: 398-399. 
Smith, C.U.M. 1976. The Problem of Life. Wiley, Nueva York, EEUU.

Strohman, R. 1997. The Coming Kuhnian Revolution in Biology. Nat. Biotechnol. 15: 194-200.

Strent, G.S. 1978. That was the molecular biology that was. Science 160: 390-395.

Van Leeuwenock, A. 1677. Observations concerning little animals in rain-, well-, sea- and snow-water. Philos. T. Roy. Soc. 11: 821-831. Reimpreso en 1999.
In T.D. Brock (ed.). Milestones in Microbiology, 1540 to 1940 . American Society for Microbiology, Washington D.C., EEUU.

Von Bertalanfyy, L.1950. The Theory of Open Systems in Physics and Biology. Science 111: 23-29.

Wallin, I.E. 1927. Symbioticism and the Origin of Species. Williams \& Wilkings, Baltimore, Maryland, EEUU.

Watson, J.D. \& F.H.D. Crick. 1953. A structure for deoxyribose nucleic acid. Nature 171: 737-738. 
